\title{
Evidence of gravity waves into the atmosphere during the March 2006 total solar eclipse
}

\author{
C. S. Zerefos ${ }^{1,3}$, E. Gerasopoulos ${ }^{1}$, I. Tsagouri ${ }^{1}$, B. E. Psiloglou ${ }^{1}$, A. Belehaki ${ }^{1}$, T. Herekakis ${ }^{1}$, A. Bais ${ }^{2}$, S. Kazadzis ${ }^{2}$, \\ C. Eleftheratos ${ }^{3}$, N. Kalivitis ${ }^{4}$, and N. Mihalopoulos ${ }^{4}$ \\ ${ }^{1}$ National Observatory of Athens, V. Pavlou \& I. Metaxa, P. Penteli, 15236, Athens, Greece \\ ${ }^{2}$ Aristotle University of Thessaloniki, Physics Department, Laboratory of Atmospheric Physics, Thessaloniki, Greece \\ ${ }^{3}$ Foundation for Biomedical Research, Academy of Athens, Greece \\ ${ }^{4}$ University of Crete, Chemistry Department, Environmental and Chemical Processes Laboratory, Crete, Greece
}

Received: 26 April 2006 - Published in Atmos. Chem. Phys. Discuss.: 31 May 2007

Revised: 12 September 2007 - Accepted: 18 September 2007 - Published: 26 September 2007

\begin{abstract}
This study aims at providing experimental evidence, to support the hypothesis according to which the movement of the moon's shadow sweeping the ozone layer at supersonic speed, during a solar eclipse, creates gravity waves in the atmosphere. An experiment was conducted to study eclipse induced thermal fluctuations in the ozone layer (via measurements of total ozone column, ozone photolysis rates and UV irradiance), the ionosphere (Ionosonde Total Electron Content - ITEC, peak electron density height - hmF2), and the troposphere (temperature, relative humidity), before, during and after the total solar eclipse of 29 March 2006. We found the existence of eclipse induced dominant oscillations in the parameters related to the ozone layer and the ionosphere, with periods ranging between 30 $40 \mathrm{~min}$. Cross-spectrum analyses resulted to statistically significant square coherences between the observed oscillations, strengthening thermal stratospheric ozone forcing as the main mechanism for GWs. Additional support for a source below the ionosphere was provided by the amplitude of the oscillations in the ionospheric electron density, which increased upwards from 160 to $220 \mathrm{~km}$ height. Even though similar oscillations were shown in surface temperature and relative humidity data, no clear evidence for tropospheric influence could be derived from this study, due to the modest amplitude of these waves and the manifold rationale inside the boundary layer.
\end{abstract}

Correspondence to: C. Zerefos

(zerefos@geol.uoa.gr)

\section{Introduction}

Gravity waves (GWs) constitute an essential motion component of the atmospheric circulation due to their important contribution in the momentum and energy budget and in the wind systems of the atmosphere (Fritts and Alexander, 2003). Their role in weather, climate and atmospheric chemistry is very important. In particular, they can transport energy and momentum between different atmospheric regions and disturb the balanced state or initiate and modulate convection and subsequent hydrological processes (e.g. Mapes, 1993). The initiated by GWs convection, can result to formation of clouds (e.g. orographic cirrus, polar stratospheric and mesospheric; Dörnbrack et al., 2002), modify chemistry, and trigger numerous processes (e.g. Voigt et al., 2000). During their dissipation phase, they contribute to the vertical transport and mixing of chemical species and influence momentum and energy in the upper troposphere/lower stratosphere and in the mesosphere and lower thermosphere (e.g. Hays et al., 2003).

A varying number of sources are believed to generate GWs at lower levels of the atmosphere including topography, convective and frontal activity, wind shear and geostrophic adjustment, while at greater heights their sources include nonlinear wave-wave interactions, auroral currents, ion drag and Joule heating but also the differential heating of the atmosphere at dawn and dusk terminator and during solar eclipses (Fritts and Luo, 1993 and references therein).

Chimonas and Hines (1970) were the first to suggest that during a solar eclipse the disturbance of the heat balance along the supersonic travel of the trajectory of the moon's shadow could generate GWs. The source of these waves was assumed to be either at higher altitudes e.g. at around $90 \mathrm{~km}$

Published by Copernicus Publications on behalf of the European Geosciences Union. 
where molecular oxygen heating begins (Chimonas, 1970), or at lower altitude e.g. water vapor IR absorption (Lamb waves) and the ground cooling (Chimonas and Hines, 1971; Chimonas, 1973). Morover, in both Chimonas (1970) and its subsequent follow on study of Firtts and Luo (1993), thermal cooling of the stratospheric ozone layer as the forcing function of GWs during a solar eclipse was considered. Eckermann et al. (2007), with their high-altitude global numerical weather prediction model, recently simulated an induced radiative cooling rate in the stratosphere, 2-3 times larger than assumed in these earlier stratospheric bow wave models. In all cases, the source ambiguity makes subsequent experimental studies seeking evidence of eclipse-generated gravity waves, particularly complicated.

There have been a number of attempts to detect ground level atmospheric pressure waves resulting from solar eclipses. The periods of such waves range from the order of $1 \mathrm{~min}$ to $1 \mathrm{~h}$ or so, the decay times range from half the wave period upwards, and the ground level amplitude is unlikely to exceed $0.1 \mathrm{hPa}$, and is typically far less (Jones, 1999). In only few cases does the balance probability lie in favour of a detection of such waves (Jones, 1999; references therein). Anderson et al. (1972) reported on surface pressure fluctuations in the range 15-150 min and Seykora et al. (1985) found a surface pressure response with a period of about $4 \mathrm{~h}$ and a speed of $320 \mathrm{~m} \mathrm{~s}^{-1}$. The amplitudes of these waves were larger than those predicted by Chimonas (1970), but agree well with the $0.1-0.5 \mathrm{hPa}$ range modelled recently by Eckermann et al. (2007).

A limited number of attempts to detect $\mathrm{GW}$ signals on total ozone have been made. Mims and Mims (1993) identified a sequence of 4-5 nearly uniformly spaced fluctuations, however with small periods (4.5-7.2 min), on total ozone series, using a TOPS (Total Ozone Portable Spectrophotometer), but the linkage with eclipse induced GWs appears weak. Zerefos et al. (2000), deploying power spectral analysis on erythemal irradiance, revealed a significant oscillation in the ozone layer with a period of about $20 \mathrm{~min}$.

In the ionosphere, waves with a period of $10-40 \mathrm{~min}$ have been measured at more than $500 \mathrm{~km}$ from the zone of totality (Singh et al., 1989), traveling at subsonic (Davis and da Rosa, 1970) or supersonic velocities (Hanuise et al., 1982). Lastly, a source location has been identified in the thermosphere at $170 \mathrm{~km}$ altitude due to reduced heating by absorption of extreme ultraviolet solar radiation, based on the analysis of ionosonde measurements (Liu et al., 1998; Altadill et al., 2001; Sauli et al., 2006), while larger periods of about $1 \mathrm{~h}$ have also been reported (Altadill et al., 2001). Prior to those observations, the idea of an in-situ thermospheric wave source was highlighted by various modeling studies (Ridley et al., 1984; Roble et al., 1986; Müller-Wodarg et al., 1998).

Despite decades of research, observational evidence for a characteristic bow-wave response of the atmosphere to eclipse passages remains equivocal (Eckermann et al., 2007). In this work, an attempt to shed light on the generation of
GWs during solar eclipses is made, with measurements at the three critical layers in the atmosphere namely the troposphere, the stratosphere and the ionosphere. The main goal is to provide experimental evidence supporting the initial hypothesis that the cooling of the ozone layer in the stratosphere by the moon shadow travelling at supersonic speed during the eclipse, constitutes a source of gravity waves propagating both upwards and downwards.

\section{Instrumentation}

Ultraviolet direct and global solar spectral measurements were performed at Kastelorizo $\left(36^{\circ} 09^{\prime} \mathrm{N}, 29^{\circ} 35^{\prime} \mathrm{E}\right)$, Thessaloniki $\left(40^{\circ} 38^{\prime} \mathrm{N}, 22^{\circ} 57^{\prime} \mathrm{E}\right)$ and Athens $\left(38^{\circ} 03^{\prime} \mathrm{N}, 23^{\circ} 52^{\prime} \mathrm{E}\right)$ using Brewer spectroradiometers (MKIII, MKII and MKIV, respectively). A map with the location of the above stations with regard to eclipse path and circumstances can be found in Gerasopoulos et al. (2007) ${ }^{1}$. The characteristics of the instrument and details about their calibration procedures are described in detail by Bais et al. (1996). The three instruments followed the same measuring schedule on the eclipse day (29 March) and on the previous day. For this study the operating software of the instrument was modified to allow the alternating measurement (every $30 \mathrm{~s}$ ) of global and direct spectral irradiance at 6 wavelengths between 302 and $320 \mathrm{~nm}$ that are used for measuring total column ozone and columnar $\mathrm{SO}_{2}$. These measurements were performed from 07:30 UTC until 14:30 UTC. More details are given by Blumthaler et al. (2006) and Kazadzis et al. (2007).

Ozone photolysis frequencies $\left(\mathrm{JO}^{1} \mathrm{D}\right)$ have been also calculated from the Brewer spectroradiometer global irradiance measurements following the methodology described in Kazandzis et al. (2004). JO ${ }^{1} \mathrm{D}$ measurements have been also conducted at Finokalia, with a filter radiometer - Meteorologie Consult, Germany (Gerasopoulos et al., 2006). We have also used UV measurements from the Greek UV monitoring network (http://www.uvnet.gr), equipped with NILUUV multi-channel radiometers, providing UV irradiance at five wavelength bands centered at 305, 312, 320, 340 and $380 \mathrm{~nm}$ (Kazantzidis et al., 2007). Meteorological measurements at a number of sites including Kastelorizo and Finokalia have been also conducted during the eclipse, as described by Founda et al. (2007).

Ionospheric observations from the National Observatory of Athens Digisonde (http://www.iono.noa.gr) were used for the investigation of the ionospheric response to the solar eclipse of 29 March 2006 over Athens $\left(38^{\circ} 00^{\prime} \mathrm{N}, 23^{\circ} 30^{\prime} \mathrm{E}\right)$. In particular, calculations of electron density profiles up to $1000 \mathrm{~km}$, obtained under a vertical incidence ionospheric sounding campaign, were used for the derivation of the peak electron density height, $\mathrm{hmF} 2$, and the estimation of the

\footnotetext{
${ }^{1}$ Gerasopoulos, E., Zerefos, C. S., Tsagouri, I., et al.: The Total Solar Eclipse of March 2006: Overview, Atmos. Chem. Phys. Discuss., in preparation, 2007.
} 
Ionosonde Total Electron Density, ITEC., (Gerasopoulos et al., $\left.2007^{1}\right)$. In addition, the electron densities at fixed ionospheric altitudes zones were calculated, enabling the study of electron density variations as a function of time and altitude (Altadill et al., 2001).

\section{Analysis and results}

\subsection{Methodology}

Observations from various atmospheric layers were analyzed deploying Spectral Fourier Analysis, in an effort to investigate the possible detection of GWs propagating in different atmospheric heights during the 29 March 2006 Total Solar Eclipse. In this study we have used the following parameters: i. total ozone over Kastelorizo, Athens and Thessaloniki, mainly as an index of the disturbance in the stratospheric ozone layer, additionally supported by ozone photolysis rates $\mathrm{JO}^{1} \mathrm{D}$ and $\mathrm{UV}(305 \mathrm{~nm})$ irradiance measurements, ii. the Ionosonde Total Electron Content (ITEC) as an indicator for the total ionosheric ionization disturbances, and the peak density height of the $\mathrm{F} 2$ layer (hmF2) as a first indicator for the propagation of wave-like motions in the ionosphere, iii. ground measurements of temperature and relative humidity at Kastelorizo and Finokalia.

As input data for the spectral analysis, we have used the residual time series of the above parameters. Residuals have been calculated by applying polynomial fittings to the initial time series, to remove the combined effect of the eclipse and the diurnal variability of each parameter. We have chosen the maximum period during the eclipse that almost cloud free conditions were encountered at all sites, so that the same period would be used for all parameters (10:00-11:52 UTC). Short-time contamination by light and temporary cloudiness or a very few cases of aircraft contrails (evidenced mainly on actinometric data) at each site, has been also removed by substituting the respective residual values with zeroes. For all parameters except for the ionospheric, 1 min time resolution data were available. Ionospheric parameters were available with a 4 min time resolution.

Because of the short duration of the investigated period, we have used the zero-padding method which consists in adding zeros at the end of the time series, to improve frequency resolution of the resulting power spectra, thus enhancing our ability to estimate the signal's period more accurately and discriminate close periodicities.

\subsection{Investigation of observed oscillations in the ozone layer}

For the period between 10:00 and 13:00 UTC, the total ozone column at Kastelorizo was changing on the day before the eclipse from about $335 \mathrm{DU}$ down to about $325 \mathrm{DU}$, and on the day of the eclipse it was increasing from about $290 \mathrm{DU}$ to 305 DU (Kazadzis et al., 2007). An increase of total ozone by the end of the eclipse in the range 5-24 DU is also reconfirmed from the NILU-UV measurements in a number of stations (Kazantzidis et al., 2007). During the course of the eclipse, a gradual decrease in total ozone at Kastelorizo, followed by an almost symmetric increase after the totality is observed (Fig. 1a, upper graph). This effect has been reported earlier by Zerefos et al. (2000), and it was attributed partly to the limb darkening effect and partly to the increasing influence of direct irradiance by the diffuse radiance entering the field of view of the total ozone instruments. Blumthaler et al. (2006), confirmed this finding by calculating a correction for total ozone due to limb darkening. This correction was found to be very small (less than $0.01 \%)$. Therefore the most possible reason for the reduced total ozone values during the eclipse is the contamination of direct irradiance measurements by the diffuse radiation (Kazadzis et al. 2007).

Total ozone residuals at Kastelorizo are shown in Fig. 1a (lower graph). A Savitzky-Golay smoothing (2nd order moving polynomial, 10 points) is also used for the better visualization of the lower frequency fluctuations. The two vertical lines in Fig. 1a correspond to sun coverage by the moon of more than $70 \%$, corresponding roughly to a reduction in direct irradiance measurements (under normal conditions) at airmass factors of more than 3, which are usually discarded in the standard Brewer total ozone measurements (Kazadzis et al., 2007). This effect results in a smooth continuous reduction of the ozone values, which is removed by the applied polynomial fit, thus the eclipse induced oscillations in the total ozone data are added on top of this smooth reduction of total ozone. The peak-to-peak amplitude of the residuals is about $2-3.5 \%$ of the total ozone averaged over the same period, and three main oscillations were observed starting 30 min after the first contact. Cloud development a little before last contact prevented the further capture of the evolution of the waves.

Since these oscillations are observed mainly during the measurement interval influenced by the diffuse radiation, we have used two additional parameters to express total ozone variability and confirm the existence of the oscillations, the photolysis rate of the reaction of $\mathrm{O}_{3}$ to $\mathrm{O}\left({ }^{1} \mathrm{D}\right), \mathrm{JO}^{1} \mathrm{D}$ and $\mathrm{UV}$ irradiance at $305 \mathrm{~nm}$. $\mathrm{JO}^{1} \mathrm{D}$ is mainly sensitive to the total column ozone, but also to the total aerosol optical depth, aerosol growth with relative humidity and by clouds depending on the optical depth of the cloud (Ruggaber et al., 1994). Moreover, UV irradiance at $305 \mathrm{~nm}$ exhibits maximum ozone absorption compared to higher wavelengths provided by the NILU-UV radiometers (Kazantzidis et al., 2007). It should be noted that the effect of diffuse irradiance that was regarded as the reason for the biased total ozone measurements during the eclipse, has no influence on the Brewer irradiance measurements, and consequently on the derived $\mathrm{JO}^{1} \mathrm{D}$ data.

$\mathrm{JO}^{1} \mathrm{D}$ measurements at Kastelorizo and Finokalia are shown in Figs. $1 \mathrm{~b}$ and c (upper graphs) with the respective polynomial fittings. $\mathrm{JO}^{1} \mathrm{D}$ residuals are presented in the 

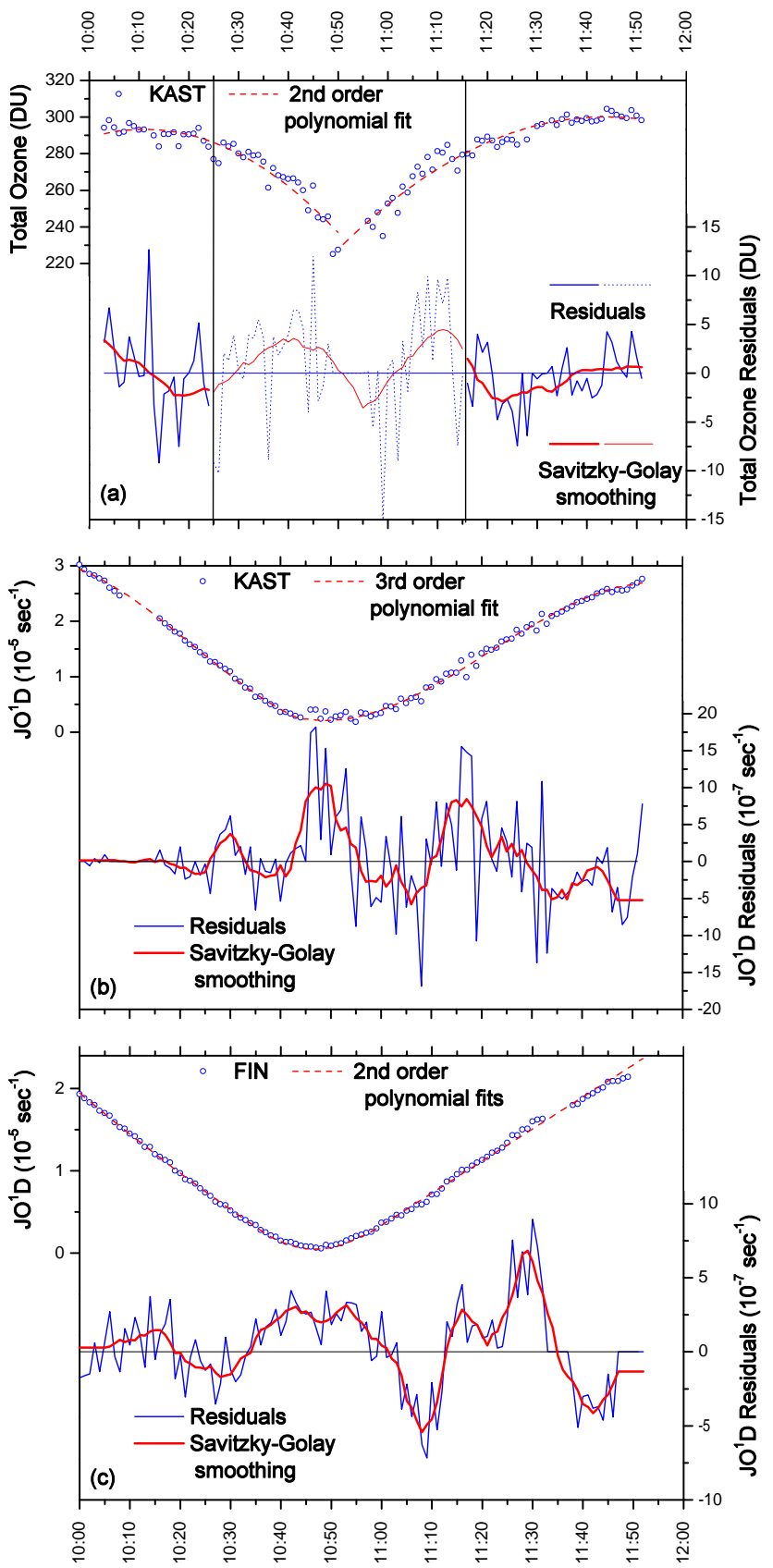

Fig. 1. (a) Upper: total ozone over Kastelorizo during the eclipse and second order polynomials fitted on the data, Lower: total ozone residuals and a Savitzky-Golay (2nd order moving polynomial, 10 points) smoothing line. The two vertical lines correspond to sun coverage by the moon of more than $70 \%$ and residuals and smoothing line during this period are presented by dot and thin (red, continuous) lines, respectively, (b) Upper: $\mathrm{JO}^{1} \mathrm{D}$ at Kastelorizo (KAST) during the eclipse and a third order polynomial fitted on the data, Lower: $\mathrm{JO}^{1} \mathrm{D}$ residuals and a Savitzky-Golay smoothing line, and (c) Upper: $\mathrm{JO}^{1} \mathrm{D}$ at Finokalia (FIN) during the eclipse and second order polynomials fitted on the data, Lower: $\mathrm{JO}^{1} \mathrm{D}$ residuals and a Savitzky-Golay smoothing line. Time in UTC.

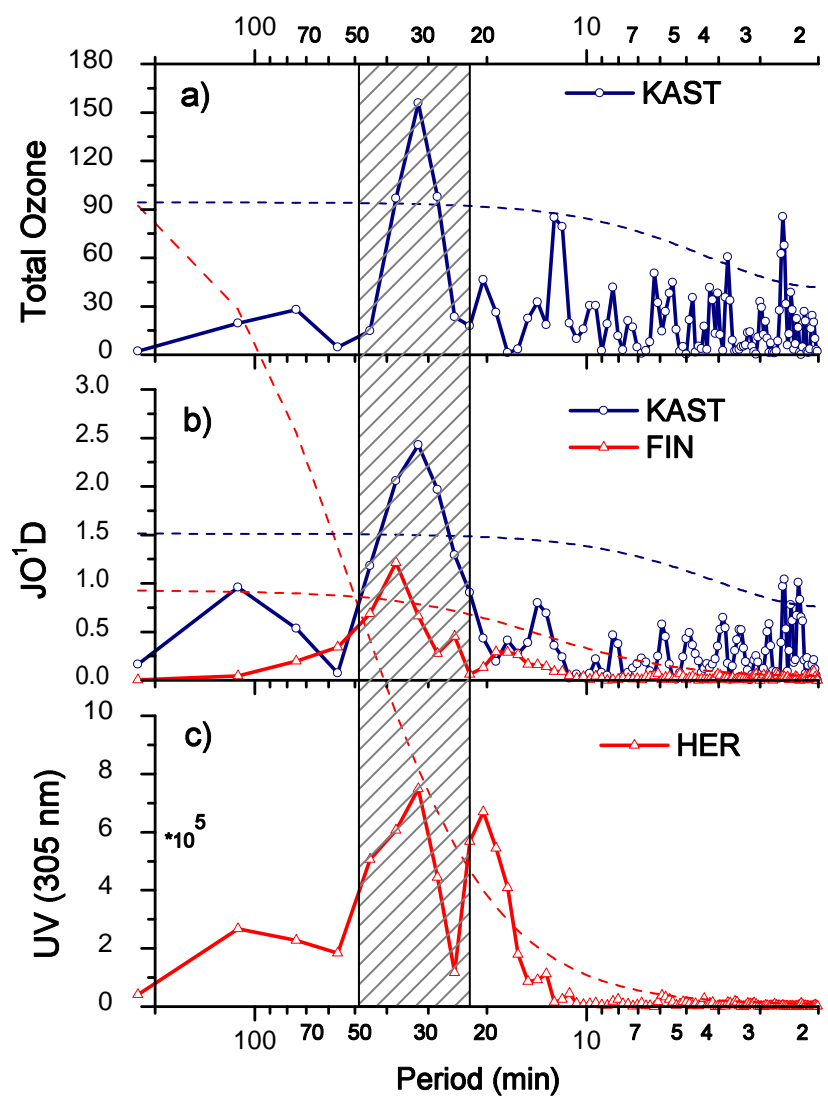

Fig. 2. Power Spectrum Analysis applied on the residuals of various atmospheric parameters during the eclipse (10:00-11:52 UTC, 29 March 2006); Y-axes correspond to the spectral estimates for the following parameters: (a) total ozone at Kastelorizo (KAST), (b) $\mathrm{JO}^{1} \mathrm{D}$ at Kastelorizo (blue line + circles) and Finokalia (FIN, red line + triangles), (c) UV $(302 \mathrm{~nm})$ at Heraklion (HER, red line + triangles), Lefkosia (LEF, blue line + circles) and Ioannina (IOA, green line + triangles reversed). Similarly colored dash lines represent the $95 \%$ confidence limits of each spectrum. Axes in (c) are divided by $10^{5}$.

lower graph of Figs. 1b and c, and the smoothing line reveals oscillations with similar characteristics. Indeed, the main oscillations found in total ozone at Kastelorizo are reproduced with a certain lag in $\mathrm{JO}^{1} \mathrm{D}$ at the same station, but also in distance from totality, at Finokalia. The average peak-to-peak amplitude of the residuals is about $8 \%$ and $10 \%$ of the $\mathrm{JO}^{1} \mathrm{D}$ over the same period, at Kastelorizo and Finokalia, respectively, however corresponding to almost half amplitudes for the more distant from totality station (Finokalia), given the different levels of $\mathrm{JO}^{1} \mathrm{D}$ at the two sites.

The oscillations are further investigated with Spectral Fourier Analysis (Fig. 2). The power spectrum of total ozone over Kastelorizo reveals a significant oscillation $(99 \%$ confidence level, not shown) with a period in the range 28$38 \mathrm{~min}$ (Fig. 2a). A secondary oscillation is found at periods $12-13$ min which approaches the $95 \%$ confidence level. 


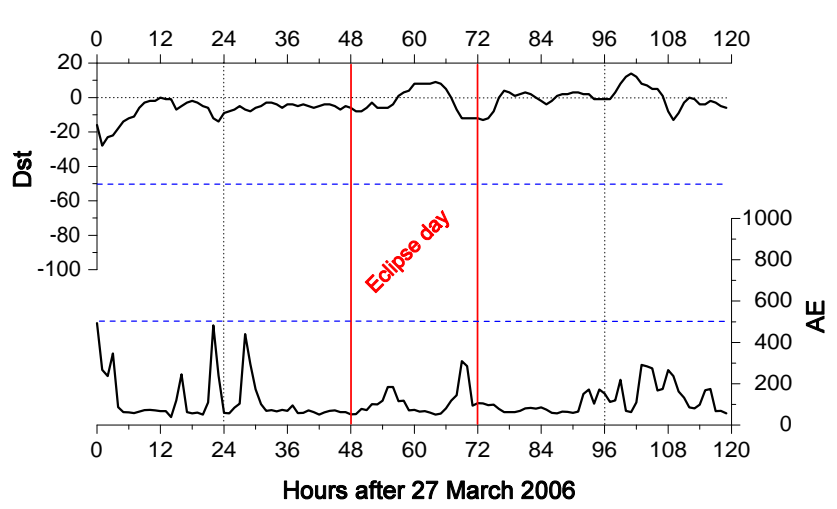

Fig. 3. Hourly records of $D_{s t}$ index (http://swdcwww.kugi.kyoto-u. ac.jp/dstdir/index.html), as indicator of the geomagnetic activity level (top panel) and of $\mathrm{AE}$ index (http://swdcwww.kugi.kyoto-u. ac.jp/aedir/index.html) indicating the level of the auroral electrojets intensity (bottom panel) for the time interval 27-31 March 2006. The blue dash lines represent indicative thresholds for the identification of considerable geomagnetic/magnetospheric disturbances.

The same process was applied on the total ozone time series at Thessaloniki (not shown). A significant oscillation (95\% confidence level) with a period of 28-32 min was found, denoting the spatial extent of the ozone layer perturbation. The amplitude of the residuals was found to be in the order of $3-$ $4 \%$ of the total ozone, averaged over the same period. The influence of clouds was much more extended on total ozone over Athens, thus hindering the attribution of fluctuations to GWs. The discussed range of periodicities could not be identified on the previous and next day spectra of the total ozone series over all sites (for the same time interval; not shown).

The power spectrum of $\mathrm{JO}^{1} \mathrm{D}$ at Kastelorizo reveals the same features with total ozone at the same station, allowing its use as a proxy for total ozone variability. The same spectrum is also revealed when 4-min averages are first extracted (not shown). The latter ensures that no bias is imposed on the cross-spectrum between the 4 min averages of total ozone and the ionospheric parameters (Sect. 3.3). The power spectrum of $\mathrm{JO}^{1} \mathrm{D}$ at Finokalia shows a peak at 3245 min (99\% significance level, not shown), while the UV irradiance at $305 \mathrm{~nm}$ spectrum at Heraklion, reveals two peaks at 28-45 min and 17-23 min. Similar oscillations were found in UV irradiance at distant stations from the peak eclipse, namely Ioannina and Nicosia (Kazantzidis et al., 2007).

Overall, a main oscillation with period in the range 30 $40 \mathrm{~min}$ is found at a number of stations with independent measurements of total ozone column and its proxies $\mathrm{JO}^{1} \mathrm{D}$ and UV irradiance, denoting an extended thermal stratospheric ozone disturbance.

\subsection{Investigation of observed oscillations in the ionosphere}

This solar eclipse took place under low geomagnetic and magnetospheric activities, providing clear advantage for the
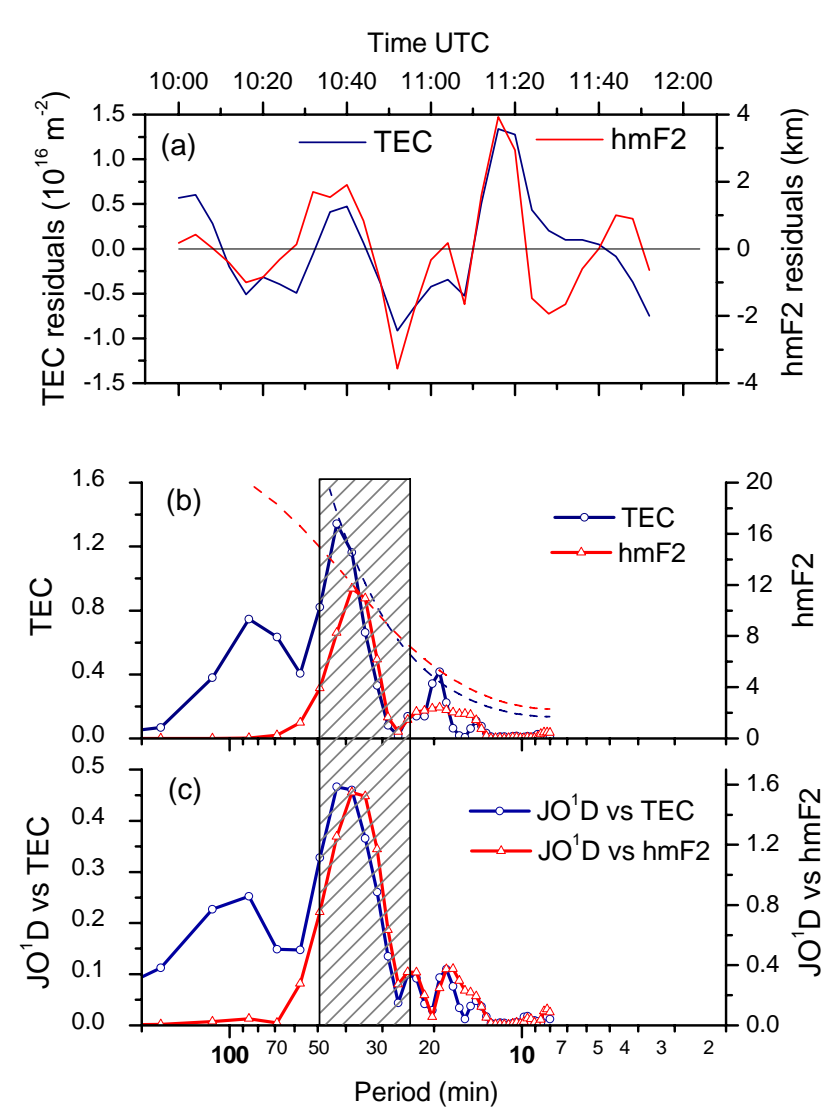

Fig. 4. (a) Ionosonde TEC and hmF2 residuals, (b) Spectrum Analysis applied on the residuals; Y-axes correspond to the spectral estimates of the parameters and similarly colored dash lines represent the $95 \%$ confidence limits of each spectrum, (c) Cross Spectrum Analysis between $\mathrm{JO}^{1} \mathrm{D}$ at Kastelorizo and ionospheric parameters; Y-axes correspond to the amplitude of the cross-spectrum for the following pairs: $\mathrm{JO}^{1} \mathrm{D}$ vs Ionosonde TEC (blue line + circles) and $\mathrm{JO}^{1} \mathrm{D}$ vs hmF2 (red line + triangles).

identification of signals from solar eclipse induced GWs in the ionosphere (Fig. 3). In particular, the geomagnetic activity remained low, since the Dst index values ranged above $-30 \mathrm{nT}$ during the whole week (27-31 March 2006), and the same holds for the magnetosheric activity. Some moderate excursions in AE index (Mayaud, 1980) recorded in very early morning or very late evening hours the days prior to the eclipse day, cannot impose an effect in the ionosphere over Athens at the local time of the eclipse occurrence (Prölss, 1995).

The complete evolution of ionospheric parameters during the eclipse is thoroughly discussed by Gerasopoulos et al. $(2007)^{1}$. Here we focus on the oscillations observed in ITEC and hmF2 presented in Fig. 4a. Three main oscillations are found almost in coincidence with those of total ozone, however the lower time resolution of these measurements and the complexity of the exact GWs source (in the horizontal and the vertical), does not allow the estimation of 


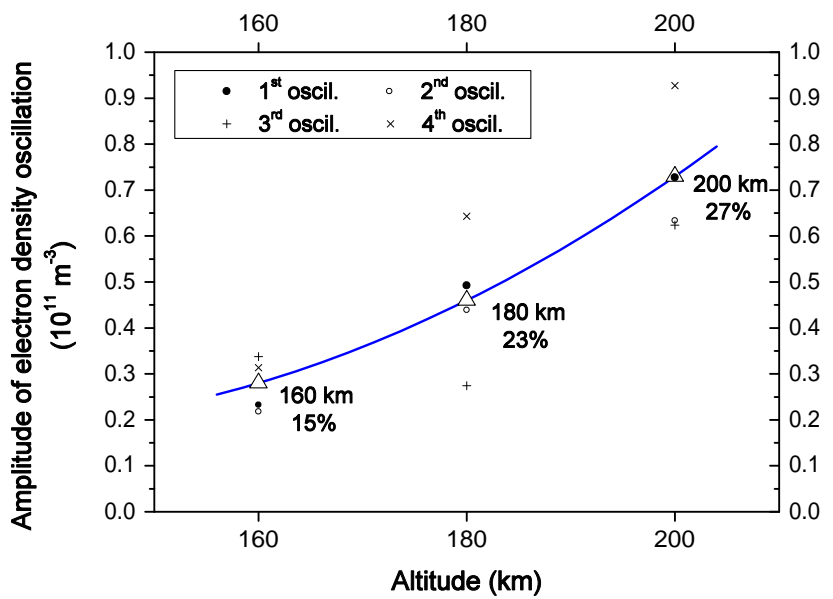

Fig. 5. Amplitudes of the electron density oscillations, calculated as the difference between successive minima and maxima at fixed altitudes $(160,180$ and $200 \mathrm{~km})$. Triangles represent the average amplitude of four oscillations at each altitude accompanied by the respective regression line (blue line), while each individual oscillation is shown with different symbol (see label). The percentage below the respective altitudes expresses the standardized to the average electron density (between first contact and maximum occultation) amplitude.

a reliable propagation velocity. The peak-to-peak amplitude of the ITEC residuals is $10-15 \%$ of the ITEC averaged over the eclipse period, while for $\mathrm{hmF} 2$ it is about $2 \%$. The power spectra of ITEC and hmF2 are shown in Fig. 4b. Significant oscillations (95\% confidence level) in the range 34-43 and 34-38 min are revealed for ITEC and hmF2, respectively. An additional peak is observed on the ITEC spectrum at 18$20 \mathrm{~min}$. Power spectra were also calculated for all "quiet" geomagnetic conditions on days between 27 and 31 March 2006, and no significant fluctuations were found, denoting that the 29 March periodicities were indeed related to solar eclipse effects.

Cross-Spectrum Analysis has been applied between $\mathrm{JO}^{1} \mathrm{D}$ at Kastelorizo and the ionospheric parameters. The amplitude of the cross spectra for the pairs $\mathrm{JO}^{1} \mathrm{D}$ vs ITEC and $\mathrm{JO}^{1} \mathrm{D}$ vs hmF2 is shown in Fig. 4c. A very distinct covariance between the frequency components corresponding to the $\sim 40$ min periodicity is found in both spectra. Significantly high square coherences were calculated, 0.93 and 0.96 for $\mathrm{JO}^{1} \mathrm{D}$ vs ITEC and $\mathrm{JO}^{1} \mathrm{D}$ vs $\mathrm{hmF} 2$, respectively, demonstrating that the ionospheric oscillations are probably driven by GWs initially formed in the stratosphere.

Variation of electron density amplitudes with height: Electron density variations at fixed ionospheric altitude zones of $20 \mathrm{~km}$ depth were additionally used to further speculate on the main source of GWs that have reached ionospheric heights. Consistent fluctuations with maximum amplitude in the altitude range of $200-220 \mathrm{~km}$ were observed during the first phase of the eclipse (Gerasopoulos et al., 2007 ${ }^{1}$ ). Such oscillations were previously reported in the literate and are attributed to solar eclipse induced GWs during or after the solar eclipse (Altadill et al., 2001; Sauli et al., 2006). In this case, the fluctuations were considerably attenuated during the solar reappearance phase. The spectrum analysis (not shown) depicted a dominant periodicity of 15-18 min, coinciding with the higher frequency oscillations in total ozone and ITEC.

The change in the amplitude of these oscillations was used to speculate on the location of the GWs source responsible for the ionospheric signal. The amplitude of these oscillations was calculated as the difference between successive minima and maxima of the electron densities at the fixed altitude zones. These oscillations were clearly present in the altitude range $140-220 \mathrm{~km}$. However, the $140-160 \mathrm{~km}$ zone was not included in our discussion here in order to keep the Elayer conditions clearly out of the analysis, since the electron concentration is very low and the detection of oscillations is ambiguous. Moreover, no such analysis was performed above $220 \mathrm{~km}$ since the main response of the ionosphere to the eclipse was gradually diminished from that height up (Gerasopoulos et al., 2007 ${ }^{1}$ ).

The amplitude of each of the four oscillations that can be identified with relative good precision, as well as the average amplitude per altitude is presented in Fig. 5. A tendency of increasing amplitude with altitude is clearly evidenced in both raw and standardized amplitudes, a result consistent with the effect of density decrease with height on the amplitude of a vertically propagating wave (Fritts and Luo, 1993).

In summary, taking into account that the observed oscillations i) are clearly present in the ionospheric height range $140-220 \mathrm{~km}$, ii) are well attenuated above $220 \mathrm{~km}$, iii) they have the same period at each height, iv) they have an important vertical propagation component, with increasing amplitude with height and v) are not of auroral origin, one could argue that they seem to originate from below the studied ionospheric heights. The above characteristics lie in favour of propagating waves attributed to the movement of the cooled spot produced by the moon's shadow in the ozone layer.

\subsection{Investigation of observed oscillations in the tropo- sphere}

The identification of GWs in the troposphere is a much more difficult task. Especially inside the boundary layer (BL), any fluctuations are subject to multiple rationales and increased uncertainty, related to meteorological or other local scale factors that may well mask the signal imposed by the propagation of GWs down to the surface.

We have used the temperature record at Kastelorizo to detect any fluctuations from GWs near the surface. The temperature drop of $2.3^{\circ} \mathrm{C}$ at Kastelorizo is shown in Fig. 6a (upper graph) accompanied by a polynomial fitting. Temperature residuals were calculated and are presented in Fig. 6a. (lower graph). The three oscillations seen in total ozone are also ob- 

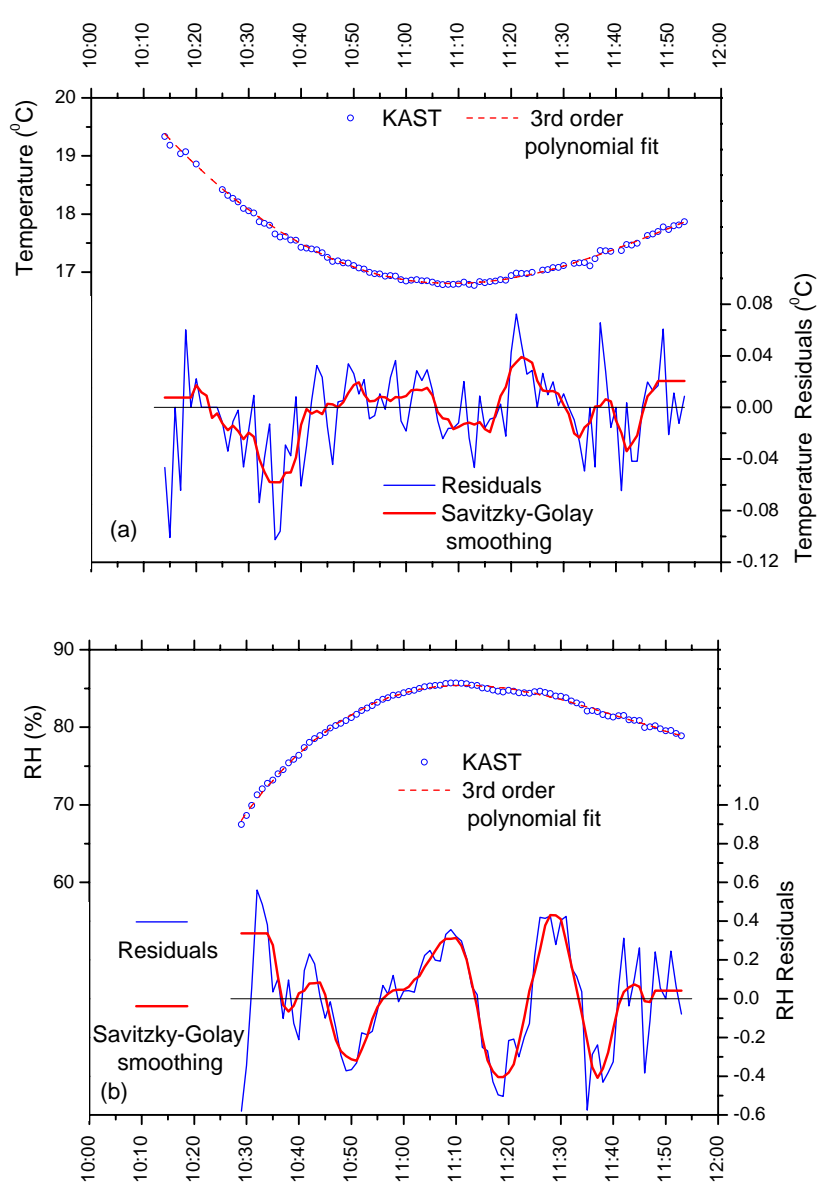

Fig. 6. (a) Upper panel: Temperature at Kastelorizo during the eclipse (open circles) and a third order polynomial fitted on the data (dash red line), (b) Upper panel: The same for RH at Kastelorizo. Lower panels in (a) and (b): Residuals of each parameter (blue line-dots) and a Savitzky-Golay (2nd order moving polynomial, 10 points) smoothing line (continuous red line). Time in UTC.

served in surface temperature with a $5-10 \mathrm{~min}$ lag, however the peak-to-peak amplitude of the residuals is rather small $\sim 0.1^{\circ} \mathrm{C}$ or $0.6 \%$ of the temperature averaged over the eclipse period, which is same order of magnitude with the sensors accuracy $\left( \pm 0.1^{\circ} \mathrm{C}\right.$; Founda et al., 2007). This amplitude is one order of magnitude lower than that predicted by Eckermann et al. (2007).

To exclude relation of this signal to instrumental noise and overcome a possible lack of confidence in the temperature oscillations we have repeated the same analysis with relative humidity, RH (Fig. 6b). The residuals shown in Fig. 6b (lower graph) once more reveal the three dominant oscillations and the peak-to-peak amplitude is $\sim 1 \%$ (absolute) or $1.2 \%$ of the RH averaged over the eclipse period. The accuracy of the RH sensor is $\pm 1 \%$, so once more the amplitude of RH signal is comparable to the instrumental accuracy, however, the fact that the oscillations are very distinct and are observed in both temperature and RH enhances our confi-

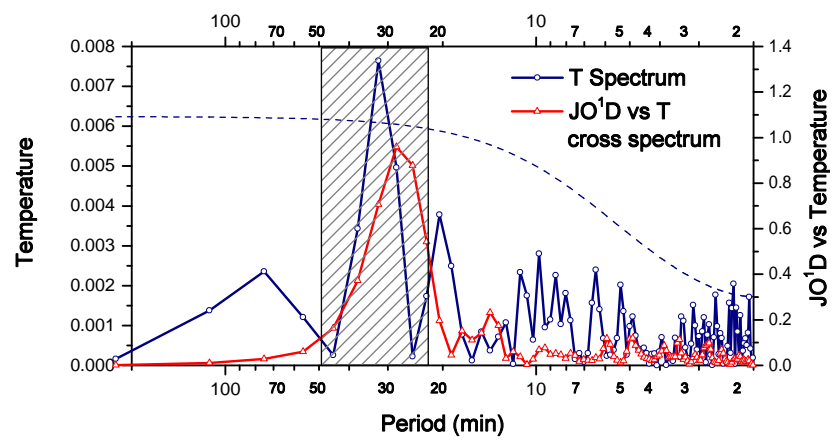

Fig. 7. Spectrum Analysis on temperature residuals and Cross Spectrum Analysis between $\mathrm{JO}^{1} \mathrm{D}$ and temperature at Kastelorizo. Yaxes correspond to the spectral and cross spectral estimates, and the colored dash line represents the $95 \%$ confidence limits of the spectrum.

dence. It should be also noted here that averaging over $1 \mathrm{~min}$ intervals (measurements recorded every $20 \mathrm{~s}$ ) has as a result to reduce the uncertainty both in temperature and $\mathrm{RH}$ measurements, and this is easily observed in Fig. 6a and b, where the noise is well separated from the oscillations.

The power spectrum of temperature at Kastelorizo is shown in Fig. 7 and a significant periodicity (95\% confidence level) in the range $28-38 \mathrm{~min}$ is revealed. Similar oscillations, with modest wave amplitudes $\sim 0.1^{\circ} \mathrm{C}$, were found in the spectra of the temperature time series at other sites namely Finokalia-Crete and Penteli-Athens (not shown). The cross spectrum between $\mathrm{JO}^{1} \mathrm{D}$ and temperature (Fig. 7) shows a strong covariance around the 30 min periodicity with significantly high square coherence, 0.97 .

Concluding, even though distinct oscillations are observed in surface temperature data at various sites, additionally reconfirmed by similar relative humidity periodicity, there is no clear evidence for GWs in the troposphere. Especially inside the boundary layer, manifold rationale could be provided for such transient perturbations in temperature and more parameters should be monitored and examined to draw safe conclusions.

\section{Summary - conclusions}

Definite observational evidence for a characteristic bowwave response of the atmosphere to solar eclipse passages, despite model calculations at various altitudes, has been still ambiguous. In this paper, we have provided combined experimental evidence to support the initital hypothesis of Chimonas and Hines (1970) that the cooling of ozone layer in the stratosphere by the supersonic travel of the moon's shadow during an eclipse, constitutes a source of gravity waves propagating both upwards and downwards. To examine the above, concurrent measurements at three critical 
layers in the atmosphere namely in the troposphere, in the stratosphere and in the ionosphere, were conducted.

Spectral Fourier Analysis revealed a dominant oscillation with period in the range $30-40 \mathrm{~min}$ in total ozone column over Kastelorizo (100\% maximum occultation), but also at larger distances, with less sun coverage (Thessaloniki, 75\% maximum occultation). It is expected that ozone in the upper stratosphere, where it maximizes and is in radiative equilibrium, would respond more rapidly to the transient cooling due to the eclipse of the sun. The eclipse induced ozone layer thermal disturbance was endorsed by $\mathrm{JO}^{1} \mathrm{D}$ and UV irradiance $(305 \mathrm{~nm})$ measurements, both sensitive to columnar ozone variability, yet denoting a spatially extended propagation of the GWs with regard to the totality axis.

The 30-40 min oscillation was also evident in the spectra of the Ionosonde Total Electron Content (ITEC) and the peak electron density height in the ionosphere (hmF2). Crossspectrum analysis between total ozone and the ionospheric parameters depicted high covariance in this range of periods. The initial argument that the source of the perturbation originates below the ionosphere was ratified by the fact that the amplitude of the electron density oscillation increased upwards from 160 to $220 \mathrm{~km}$, which is expected for a vertically propagating wave inside a mean of decreasing with height density.

The identification of the GWs oscillation in the troposphere has been attempted with records of surface temperature and relative humidity. Distinct oscillations were observed in both parameters within the period range of our interest, at various sites. However, the amplitude of these oscillations has been modest and in the same order of magnitude with the sensor's accuracy. It should be kept in mind that the intensity of the waves downwards could be considerably suppressed by the fact that the propagation takes place in a denser mean, and that inside the BL any periodical signal in the parameters subjects to manifold rationale also controlled by meteorological or other local scale factors. The above do not allow us to draw safe conclusions on the influence of eclipse induced GWs in the troposphere, and should be taken under consideration for future experiments planning.

Acknowledgements. The authors would like to thank the two anonymous reviewers for their insightful comments and $\mathrm{S}$. Eckermann for his valuable suggestions. The Dst and $\mathrm{AE}$ indices' records used in this analysis were obtained from the World Data Center for Geomagnetism, Kyoto archives (http://swdewww.kugi.kyoto-u.ac.jp/).

Edited by: P. Monks

\section{References}

Altadill, D., Sole, J. G., and Apostolov, E. M.: Vertical structure of a gravity wave like oscillation in the ionosphere generated by the solar eclipse of August 11, 1999, J. Geophys. Res., 106(A10), 21 419-21 428, 2001.

Anderson, R. C., Keefer, D. R., and Myers, O. E.: Atmospheric pressure and temperature changes during the 7 March 1970 solar eclipse, J. Atmos. Sci., 29, 583-587, 1972.

Bais, A. F., Zerefos, C. S., and McElroy, C. T.: Solar UVB measurements with the double and single monochromator Brewer ozone spectroradiometers, Geophys. Res. Lett., 23, 833-836, 1996.

Blumthaler, M., Bais, A., Webb, A., Kazadzis, S., Kift, R., Kouremeti, N., Schallhart, B., Kazantzidis, A.: Variations of solar radiation at the Earth's surface during the total solar eclipse of 29 March 2006, in: Remote Sensing of Clouds and the Atmosphere XI, edited by: Slusser, J. R., Schäfer, K., Comerón, A., Proceedings of the SPIE, Vol. 6362, doi:10.1117/12.689630, 2006.

Chimonas, G.: Internal gravity-waves motions induced in the Earth's atmosphere by a solar eclipse, J. Geophys. Res., 75, 5545-5551, 1970.

Chimonas, G.: Lamb waves generated by the 1970 solar eclipse, Planetary Space Science, 21, 1843-1854, 1973.

Chimonas, G. and Hines, C. O.: Atmospheric gravity waves induced by a solar eclipse, J. Geophys. Res., 75, p. 875, 1970.

Chimonas, G. and Hines, C. O.: Atmospheric gravity waves induced by a solar eclipse, 2, J. Geophys. Res., 76(28), 7003-7005, 1971.

Davis, M. J. and da Rosa, A. V.: Possible detection of atmospheric gravity waves generated by the solar eclipse, Nature, 226, p. 1123, 1970.

Dörnbrack, A., Birner, T., Fix, A., Flentje, H., Meister, A., Schmid, H., Browell, E. V., and Mahoney, M. J.: Evidence for inertia gravity waves forming polar stratospheric clouds over Scandinavia, J. Geophys. Res., 107(D20), 8287, doi:10.1029/2001JD000452, 2002.

Eckermann, S. D., Broutman, D., Stollberg, M. T., Ma, J., McCormack, J. P., and Hogan, T. F.: Atmospheric effects of the total solar eclipse of 4 December 2002 simulated with a high-altitude global Model, J. Geophys. Res., 112, D14105, doi:10.1029/2006JD007880, 2007.

Founda, D., Melas, D., Lykoudis, S., Lysaridis, I., Kouvarakis, G., and Petrakis, M.: The effect of the total solar eclipse of March 29, 2006 on meteorological variables in Greece, Atmos. Chem. Phys. Discuss., 7, $10631-10667,2007$.

Fritts, D. C. and Luo, Z.: Gravity wave forcing in the middle atmosphere due to reduced ozone heating during a solar eclipse, J. Geophys. Res., 98(D2), 3011-3021, 1993.

Fritts, D. C. and Alexander, M. J.: Gravity wave dynamics and effects in the middle atmosphere, Rev. Geophys., 41(1), 1003, doi:10.1029/2001RG000106, 2003.

Gerasopoulos, E., Kouvarakis, G., Vrekoussis, M., Donoussis, C., Kanakidou, M., and Mihalopoulos, N.: Photochemical ozone production in the Eastern Mediterranean, Atmos. Environ., 40, 3057-3069, doi:10.1016/j.atmosenv.2005.12.061, 2006.

Hanuise, C., Broche, P., and Ogubazghi, G.: HF Doppler observations of gravity waves during the 16 February 1980 solar eclipse, J. Atmos. Solar-Terr. Phys., 44, 963-966, 1982.

Hays, P. B., Kafkalidis, J. F., Skinner, W. R., and Roble, R. G.: 
A global view of the molecular oxygen night glow, J. Geophys. Res.-Atmos., 108(D20), 4646, doi:10.1029/2003JD003400, 2003.

Jones, B. W.: A search for atmospheric pressure waves from the total solar eclipse of 9 March 1997, J. Atmos. Solar-Terr. Phys., 61, 1017-1024, 1999.

Kazadzis, S., Topaloglou, C., Bais, A. F., Blumthaler, M., Balis, D., Kazantzidis, A., and Schallhart, B.: Actinic flux and $\mathrm{O}^{1} \mathrm{D}$ photolysis frequencies retrieved from spectral measurements of irradiance at Thessaloniki, Greece, Atmos. Chem. Phys., 4, 22152226, 2004,

http://www.atmos-chem-phys.net/4/2215/2004/.

Kazadzis, S., Bais, A., Kouremeti, N., Blumthaler, M., Webb, A., Kift, R., Schallhart, B., and Kazantzidis, A.: Effects of total solar eclipse of 29 March 2006 on surface radiation, Atmos. Chem. Phys. Discuss., 7, 9235-9258, 2007,

http://www.atmos-chem-phys-discuss.net/7/9235/2007/.

Kazantzidis, A., Bais, A. F., Emde, C., Kazadzis, S. and Zerefos, C. S.: Attenuation of global ultraviolet and visible irradiance over Greece during the total solar eclipse of 29 March 2006, Atmos. Chem. Phys. Discuss., 7, 13475-13501, 2007, http://www.atmos-chem-phys-discuss.net/7/13475/2007/.

Liu, J. Y., Hsiao, C. C., Tsai, L. C., Liu, C. H., Kuo, F. S., Lue, H. Y., and Huang, C. M.: Vertical phase and group velocities of internal gravity waves from ionograms during the solar eclipse of 24 October 1995, J. Atmos. Solar-Terr. Phys., 60, 1679-1686, 1998.

Mapes, B. E.: Gregarious tropical convection, J. Atmos. Sci., 50, 2026-2037, 1993.

Mayaud, P. N.: Derivation, Meaning and Use of Geomagnetic Indices, AGU Geophysical Monograph, 22, Washington D.C., 1980.

Mims III, F. M. and Mims, E. R.: Fluctuations in column ozone during the total solar eclipse of July 11, 1991, Geophys. Res. Lett., 20(5), 367-370, 1993.

Müller-Wodarg, I. C. F., Aylward, A. D., and Lockwood, M.: Effects of a mid-latitude solar eclipse on the thermosphere and ionosphere: A modelling study, Geophys. Res. Lett., 25, 37873790, 1998.
Prölss, G. W.: Ionospheric F-region storms in Handbook of Atmospheric Electrodynamics, II, , 195-248, CRC Press, 1995.

Ridley, E. C., Dickinson, R. E., Roble, R. G., and Rees, M. H.: Thermospheric response to the June 11, 1983, solar eclipse, J. Geophys. Res., 89, 7583-7588, 1984.

Roble, R. G., Emery, B. A., and Ridley, E. C.: Ionospheric and thermospheric response over Millstone Hill to the May 30, 1984 annular solar eclipse, J. Geophys. Res., 91, 1661-1670, 1986.

Ruggaber, A., Dlugi, R., and Nakajima, T.: Modelling Radiation Quantities and Photolysis Frequencies in the Troposphere, J. Atmos. Chem., 18, 171-210, 1994.

Sauli, P., Abry, P., Boska, J., and Duchayne, L.: Wavelet characterization of ionospheric acoustic and gravity waves occurring during the solar eclipse of August 11, 1999, J. Atmos. Solar-Terr. Phys., 68, 586-598, 2006.

Seykora, E. J., Bhatnagar, A., Jain, R. M., and Streete, J. L.: Evidence of atmospheric gravity waves produced during the 11 June 1983 total solar eclipse, Nature, 313, 124-125, 1985.

Singh, L., Tyagi, T. R., Somayajulu, Y. V., Vijayakumar, P. N., Dabas, R. S., Loganadham, B., Ramakrishna, S., Rama Rao, P. V. S., Dasgupta, A., Naneeth, G., Klobuchar, J. A., and Hartmann, G. K.: A multi-station satellite radio beacon study of ionospheric variations during solar eclipses, J. Atmos. Solar-Terr. Phys., 51, 271-278, 1989.

Voigt, C., Tsias, A., Dörnbrack, A, Meilinger, S., Luo, B., Schreiner, J., Larsen, N., Mauersberger, K., and Peter, T.: Nonequilibrium compositions of polar stratospheric clouds in gravity waves, Geophys. Res. Lett., 27(23), 3873-3876, 2000.

Zerefos, C. S., Balis, D. S., Meleti, C., Bais, A. F., Tourpali, K., Kourtidis, K., Vanicek, K., Cappellani, F., Kaminski, U., Colombo, T., Stubi, R., Manea, L., Formenti, P., and Andreae M. O.: Changes in surface solar UV irradiances and total ozone during the solar eclipse of August 11, 1999, J. Geophys. Res., 105(D21), 26 463-26473, 2000. 